\title{
Assessing first-year students' ability to critically reflect and build on their team experiences
}

\section{Dr. Nick Tatar, Olin College of Engineering}

Nick Tatar, Associate Dean of Student Affairs and Instructor of Education: Dr. Tatar received his PhD from the University of New Hampshire where he focused on student learning and student motivation during the high school to college transition. He initiated and developed a first-year seminar course at Olin College, a course that focuses on working in teams, diversity, and self-directed learning. He enjoys collaborating with other faculty members in the classroom and is invested in research, classes and assignments that provide overlap and continuity within the engineering curriculum and engineering pipeline. Nick is also a mentor for the REU program at Olin which studies the educational experiences of undergraduate engineers.

\section{Kevin A. Nguyen, Texas Tech University}

Kevin Nguyen is currently a graduate student in the Civil and Environmental Engineering department at Texas Tech University and is working towards a B.S. and M.Eng in Environmental Engineering. He has participated as an undergraduate researcher in the NSF REU Summer Experience in Engineering Education Research program at Franklin W. Olin College.

\section{Chris Aaron Gewirtz, Rose-Hulman Institute of Technology}

I'm currently a senior-year Engineering Physics student at Rose-Hulman Institute of Technology. Though I've enjoyed the technical work I've done, and devote myself now to my senior design project, I feel that education research has much to offer me, and that I have much to offer it. I think the combination of science or engineering with education provides an opportunity for me to apply my scientific curiosity towards understanding and helping people, a better opportunity than I could have predicted before doing this research. 


\title{
Assessing first-year students' ability to critically reflect and build on their team experiences
}

\begin{abstract}
Undergraduate engineering students are more likely than ever to find themselves working on project-based team assignments. This pedagogical shift toward project-based team learning environments has raised a number of questions for faculty including questions about what firstyear students are learning about themselves and their teammates while they are participating in project-based team assignments. In this study, first-year undergraduate engineering students watched a video of themselves during a design team meeting for a project-based course. They were then asked to analyze the video using one of five prompts and to provide evidence-based suggestions and feedback for themselves and their team. Using a coding framework delineated from Mezirow's theory of transformative learning, ordinal levels of self-reflection were assigned to each self-reflection essay: non-reflection (lowest level of reflection), understanding, reflection, and critical reflection (highest level of reflection). After evaluating the essays, 6\% (3) of the selfreflection essays were assessed as non-reflection, 29\% (15) were labeled as understanding, 58\% (30) earned an evaluation of reflective, and 8\% (4) were classified as critically reflective. The five self-reflection prompts provided no statistically significant difference between the levels of reflection received (chi-squared $=1.99, \mathrm{df}=4, \mathrm{p}$-value $=0.74)$. Women may show a trend of achieving higher levels of reflection than men $(\mathrm{W}=258.5$, p-value $=0.10)$. Viability of assessing levels of reflection is discussed. Suggestions for future self-reflection prompts are provided. Qualitative characteristics of critical reflectors are given.
\end{abstract}

\section{Introduction}

Undergraduate engineering students are more likely than ever to find themselves working on project-based team assignments. This pedagogical shift toward project-based team learning environments has raised a number of questions for first-year teaching faculty about how firstyear students understand their own team experiences. One way to explore how students understand their own team experiences on project-based assignments is through a video assisted self-reflection assignment ${ }^{1}$. Video assisted self-reflection is a scaffolded self-reflection assignment that aims to help students think about their experience and gain more insight about their team experience by returning directly to the experience. Little research has been done on how video assisted self-reflection may help engineering students self-reflect. Studies do suggest that using video to assist self-reflection is a worthy exercise ${ }^{2-5}$. Assessing levels of reflection in essays has also been evaluated with varying degrees of success ${ }^{6-9}$. The purpose of this study was to attempt to understand and assess reflection as performed by first-year undergraduate engineering students while they participate in project-based team experiences. Our hope is that 
this analysis and assessment will be useful to students and faculty as they begin to think critically about their project-based team experiences and assignments.

From the standpoint of Kolb’s experiential learning, reflection is necessary in order to incorporate the lessons learned from concrete experience into conceptual frameworks and understandings of the material ${ }^{2}$. Likewise, reflective thinking is an essential component of Mezirow's transformative learning theory ${ }^{10}$ which provides a lens for determining the nature and extent of the reevaluations of one's actions or beliefs when returning to an experience. Using a rubric derived from this theoretical lens ${ }^{7}$ the research team explored the following questions:

- What is an effective method for assessing self-reflection?

- Do students use self-reflection effectively to understand their team experiences?

- Are video-supported self-reflection exercises effective at promoting learning about projectbased-team experiences?

- Do different self-reflection prompts promote different levels of self-reflection?

- Are there gender differences when it comes to self-reflection and learning about projectbased team experiences?

\section{Literature Review}

Self-reflection has been used in a range of fields including teaching, medicine, and sports. Researchers and educators are now beginning to explore the role of self-reflection in undergraduate engineering. For example, self-reflection has been used to understand first-year students' conceptions about teamwork and design ${ }^{11}$, mentoring ${ }^{12}$ and service learning ${ }^{13}$. Critical reflection assessments have also been used to draw important parallels in first year students between quality of work and a student's ability to critically reflect ${ }^{14}$. As more researchers begin to use reflection data to make correlations and draw contrasts, new models and methods are needed to successful delineate levels of reflections in first year engineering students.

Mezirow's definition of reflection provides a starting point for understanding and assessing different levels of self-reflection ${ }^{15}$. Mezirow defines reflection as the process of addressing distortions in our assumptions and countering our errors in problem solving ${ }^{15}$. Mezirow defines critical-reflection as the application of this process to the assumptions as a whole. In this sense, reflection is a kind of "validity testing." Reflection is the testing of existing conceptual understandings, strategies, and context bound assumptions, while critical-reflection is the testing of the presumed characteristics of a context, of whether a certain context is applicable or appropriate, and of the rationale that used to identify a context.

Mezirow further describes categories of non-reflection and reflection ${ }^{15}$. Non-reflection is broken down into two categories: habitual action and thoughtful action without reflection. 
Habitual action is that to which no conscious deliberation is paid, and when an experience is simply thought of as having no potential to be explored. Thoughtful action is that in which a conceptual framework is employed without being verified or challenged. There is exploration of an experience but only to result in what is already known. Ex post facto (after the experience or event) reflection is broken down into content reflection, process reflection, and premise reflection. These different kinds of reflection are described using "meaning schemes", defined as "the constellation of concept, belief, judgement, and feeling which shapes a particular interpretation", and higher order "meaning perspectives", defined as "the structure of cultural and psychological assumptions within which our past experiences assimilates and transforms new experience". Content reflection is described as learning within meaning schemes, in order to expand, compliment or revise existing systems of knowledge (Ex: recognizing one technique as more effective than another). Process reflection is described as learning new meaning schemes, ones that are compatible with the learners existing meaning schemes and perspectives (Ex: recognizing oneself as having become more proficient in light of practice). Premise reflection, otherwise known as critical-reflection, is learning in order to transform meaning perspectives (Ex: redefining "proficiency” for oneself), allowing for completely different meaning schemes.

Schön describes the reflective practitioner as someone who can compare what is thought to be known to a theoretical understanding and can effectively respond to unexpected outcomes in order to solve a problem at-hand ${ }^{16}$. Schön uses the term "knowledge-in-action" to describe how a professional demonstrates what they know when solving a problem, though the knowledge itself may be tacit or hard for the practitioner to describe. This is directly related to Mezirow's habitual and thoughtful action, as experiences are approached while maintaining the set of assumptions and conceptual connections used to understand a problem. Reflection, as defined by Schön, is the process by which a practitioner develops and modifies this knowing-in-action, and reflection can only be done when paired with an action, and is separated into three types: reflection-before-action, reflection-in-action, and reflection-on-action. Reflection-on-action is the only definition being employed in this case, as these students reflect on actions after they have already happened, ex post facto, in order to affect how they might act in the future.

Kolb describes the process of learning from experience as a cycle (Figure 1), and cites reflection as the part of the learning process by which concrete experience is used to generate, validate, or otherwise affect conceptual frameworks or knowledge systems ${ }^{2}$. Reflection in this cycle is a necessary step for incorporating experience into one's knowledge.

Schön also considered reflection to be a necessary aspect of design and considered it a process for developing a tacit understanding of problem solving that goes beyond the "technical rationality" and specific epistemology taught to designers in the formal setting ${ }^{16}$. Blockley uses the definition of a reflective practitioner to characterize engineering thinking in contrast to scientific thinking ${ }^{17}$. Reflection on action can allow designers to reflect on their path through 
design and to explore other avenues for solving their problem ${ }^{18}$. Considering that the design teams being examined are meant to mimic closely the user oriented design experience, experiential learning dictates that reflection is a necessary part of learning. Reflection has also been shown to allow students to identify the aspects that contribute to successful teamwork and allow them to develop understandings in common with highly experienced engineers ${ }^{18}$.

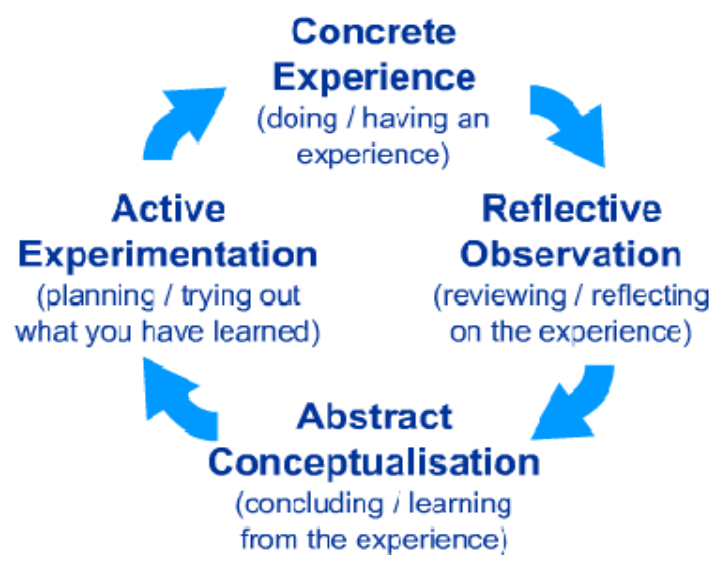

Figure 1: Kolb’s experiential learning cycle

Rubrics for assessing levels or degrees of reflection have most recently come from the fields of nursing and medicine. For example, students in internal medicine clerkships were asked to write reflective essay or two blog posts, and the level of reflection and themes of reflection (being humanistic, being a student, clinical learning, professional behavior) were successfully coded and compared between groups of students ${ }^{19}$. In a different student fourth and fifth year medical students reflected on two interactive video cases and were assigned a reflection score by their peers based on a specially developed rubric ${ }^{20}$. Kember's most recent rubric for determining levels of reflection from student writing comes from nursing education ${ }^{5,7,21}$.

Though reflective practice has been shown to be instrumental in promoting deeper understanding of educational material, and allows students to evaluate their mode of thinking and their actions, and is considered by some to be a necessary aspect of design, we are only beginning to study the relationship between engineering student's learning and reflection ${ }^{1,18,23,24}$. Sabag et al. demonstrates that engineers do reflect when prompted and describes particular situations that inspire students to reflect, but there have not been determinations of levels of reflection, and only one found characterization of how engineers reflect with video ${ }^{1,3}$.

Previous studies have included suggestions as to how to incorporate reflective thinking into a curriculum. Sabag et al. found that reflection could be encouraged through mediation on part of either a facilitator, or a teammate in the case of group reflection ${ }^{1}$. By Schön's definition, there is only so much that can be directly taught in a classroom, and knowledge-in-action must 
be developed in response to the process of solving an actual problem ${ }^{12}$. Kolb supports this with the step of reflection coming right after concrete experience ${ }^{2}$. Both Sabag and Nussbaum and Novick, seem to agree that a kind of “dissonance" or "surprising irregularity" can be used to inspire reflection ${ }^{1,25}$. In the case of Nussbaum and Novick, they provide a framework for replacing students possibly incorrect mental models, the first step of which is to introduce a dissonance between reality and the standing mental model ${ }^{25}$. Walther et al. suggests the use of Accidental Competency discourse as a tool for facilitating student reflection ${ }^{24}$. Chan suggests that community service learning may provide students with more opportunities to reflect ${ }^{23}$.

Kember asserts that, based off of Mezirow, reflection can be reliably assessed to be one of four categories ${ }^{7}$. This framework is meant to be applied to adults, people with existing meaning schemes and meaning perspectives, so it can be applied to college age engineering students. The protocol is meant to characterize the reflections of the students and is not meant to determine the accuracy of the conclusions that students derive from reflection. Both Mezirow and Schön also abandon the attempt to determine directionality or the efficacy of reflection. While critical-reflection holds the most potential for providing resilient solutions to problems, that is not the only outcome.

In this context, reflection is defined as the cognitive process by which actions and beliefs or, more accurately in Mezirow's language: meaning schemes and meaning perspectives, are analyzed and "validity tested" when compared against experience, leading to the generation of new knowledge or support for existing knowledge.

\section{Methods}

The study was performed at a small undergraduate engineering college. The students in this study are all first-year students. Students in this study were all taking two required courses: a design course in which the second half of the semester is devoted to an engineering design project; and an introductory seminar course that covers topics such as team dynamics. While working on the final project in the design course, students in the seminar were asked to video a team meeting of their design group approximately two weeks into the project. They were then asked to analyze the video using one of five different prompts and to provide suggestions for themselves and their team based on that analysis:

1. Team roles: Categorize the role of each team member during the meeting using the Belbin Team Roles handout. Provide examples that illustrate connections to the theory you're applying.

2. Non-verbal cues: Discuss how non-verbal cues were used by each group member to encourage discussion and decisions or show disapproval and apathy. For example, how 
were team members using eye contact and arm gestures during the meeting? How where head nods and "uh-hmms" being used? How did you read these cues during the meeting?

3. Decisions: Summarize how a decision was made. Include notes about who offered ideas; what ideas were introduced, what ideas were shot down; and your theory on why one idea was pursued.

4. Memory comparison: Watch yourself in the video of your meeting and compare it to your own memories of the meeting. Are you surprised by anything? How did you act? For example, did you mask discouragement? Did you express approval verbally and/or non-verbally? Did you change your mind during discussion, and if so, why did you change your mind? What was your read of others during the meeting? Did you feel like you owned part of a decision or where you just along for the ride? What were your instincts telling you during the meeting and did you act on them? Did you agree with how decisions were being made?

5. Quantitative analysis: Use counting or time to help analyze your meeting. For example:

- Count the number of time each team member spoke or interrupted each other to explore team player dynamics or the possible role of gender in the meeting

- Keep track of how long team members speak to explore decision making processes and the role team members played.

After completing the assignment, students (84) were given the option to submit their selfreflection papers and video for this research study. 56 students agreed to have their selfreflection essays in the study.

The researchers modified Kember's original coding scheme in order to relate the rubric to the self-reflection essays and the most recent research on self-reflection. 13 essays were used to refine the rubric and 20 essays were randomly used to test inter-coder reliability. 4 essays were disqualified in the final results because they were used extensively for practice and refining the rubric. 52 self-reflection essays were used in the final analysis. The researchers began the study by assigning a level of reflection to each paper based on the reflection assessment framework described by Kember ${ }^{7}$ : Non-reflection, Understanding, Reflection, and Critical-Reflection.

Non-reflection is assigned to a paper that is primarily descriptive in nature. The student does not refer explicitly to the reasoning used when performing thoughtful action or when evaluating the situation. The team experience is described without any thought given to alternative situational outcomes or to contextual factors. These papers could be described as action focused, e.g. using invalidated assumptions or unsupported opinions ${ }^{6}$. The conclusions are 
“concrete, as-a-matter-of-fact” with minimal evidence of abstract thinking ${ }^{9}$. These papers are rather impersonal and do not explore the team experience in depth.

Understanding, also known as thoughtful action, is different from habitual action as the student tries to understand a concept or theory behind the topic, possibly stating the reasoning behind their action, or making an evaluation. They recognize alternative situational outcomes but these alternatives arise from a theory that remains external to themselves, and do not raise implications for changes in their behavior or beliefs. They generate suggestions but fail to provide reasons why the suggestions would work in terms of practical application to themselves or others. The reasoning for their suggestions may not be rooted in a situation the student has experienced, but rather in a theoretical model.

Reflection, which is comprised of Mezirow's descriptions of content and process reflection, is achieved when the student observes and explains an underlying concept or theory and relates it back to how it affects themselves or the team ${ }^{11}$. Their observations have implications for changes in the behavior of themselves or the team. The student shows application of the theory by using it to explain their own personal experiences with insights that go beyond the academic level ${ }^{7}$. These individuals may link action to knowledge, observe the relationship between principles or between a principle and a practice ${ }^{6}$. The key difference between reflection and understanding is that there is no longer an externally imposed theory, and the experience provides a lesson, or change of a knowledge structure.

Critical-reflection, also known as premise reflection, is the highest level of reflection described by Mezirow ${ }^{11}$. These students articulate a transformative learning experience by recognizing their own tacit theories and evaluating them in light of their observations. The students will mention their prior beliefs and knowledge and discuss how their conceptual framework allowed them to assess an experience, and how that experience challenged their beliefs and knowledge ${ }^{7,9}$. The students may change to a new perspective or reaffirm their prior conceptual framework, although reaffirmation is unlikely because failure usually motivates selfreflection ${ }^{1}$. This transformative experience will likely provide a more resilient and generally applicable perspective. Critical-reflections are unlikely to occur often ${ }^{7,9}$.

Assessing the level of reflection from the students' papers was on the whole paper level. Previous studies demonstrate papers are best understood holistically, not by coding each sentence $^{7,9}$. Instead of trying to assess the merit or strength of key words or individual phrases or sentences within the self-reflection essays, they were assessed by the overall direction and the sum of the parts. Wong et. al found that the inclusion of "finer levels of reflection" was more problematic and considerably less reliable and that self-reflection essays often contain large sections of non-reflection such as descriptive text ${ }^{7,9}$. 
Members of the researcher team read all the papers with personal identifying information removed including the gender of the author. Researchers were concerned about gender bias, as the researchers were aware of previous studies that had suggested women may be better at selfreflection than men ${ }^{3}$. Students' papers were coded for each of the four categories and a summary explain was written each for paper to support inter-coder reliability if different levels of selfreflection were assigned. Data analysis compared the levels of reflection, levels of reflection by gender, and levels of reflection by the type of prompted used. Gender differences in the levels of reflection were assessed using a two sample Wilcoxon test. Differences between prompts and their corresponding levels of reflection were assessed using a Kruskal Wallis test. Both tests reflect the non-parametric and ordinal characteristics of the data. When there was a disagreement self-reflection levels, the differences in codes were discussed until a consensus was reached. If a consensus could not be reached, then the lower of the two levels assigned between the two researchers was chosen.

\section{Results}

To measure the inter-rater agreement Cohen's kappa was calculated to assess the magnitude of agreement between the readers and the four categories that were used to describe the level of reflection. Initial levels of reflections assigned between the two researchers are shown in Table 1. The modified Kember rubric showed a fair amount of agreement between the readers with a kappa value of $0.40(n=20)$. Cohen's Kappa value went up to $0.57(n=56)$ when the modified rubric was stripped of any modifications and Kemper's original rubric was used.

Table 1

Types of Disagreement Between Researchers $(n=19)$

\begin{tabular}{|l|l|l|}
\hline Type of Disagreement & \# of Initial Disagreements & \# of Continued Disagreements \\
\hline Non-reflection vs. Understanding & 0 & 0 \\
\hline Understanding vs. Reflection & 16 & 2 \\
\hline Reflection vs. Critical-Reflection & 3 & 1 \\
\hline
\end{tabular}

The majority of the self-reflection essays were classified as reflection essays $(n=30)$, the second highest level of self-reflection. Relatively few essays earned the lowest level in the rubric, non-reflection $(n=3)$, or critical reflection $(n=4)$, the highest level of reflection. The second most common assessment was understanding (Figure 2). 


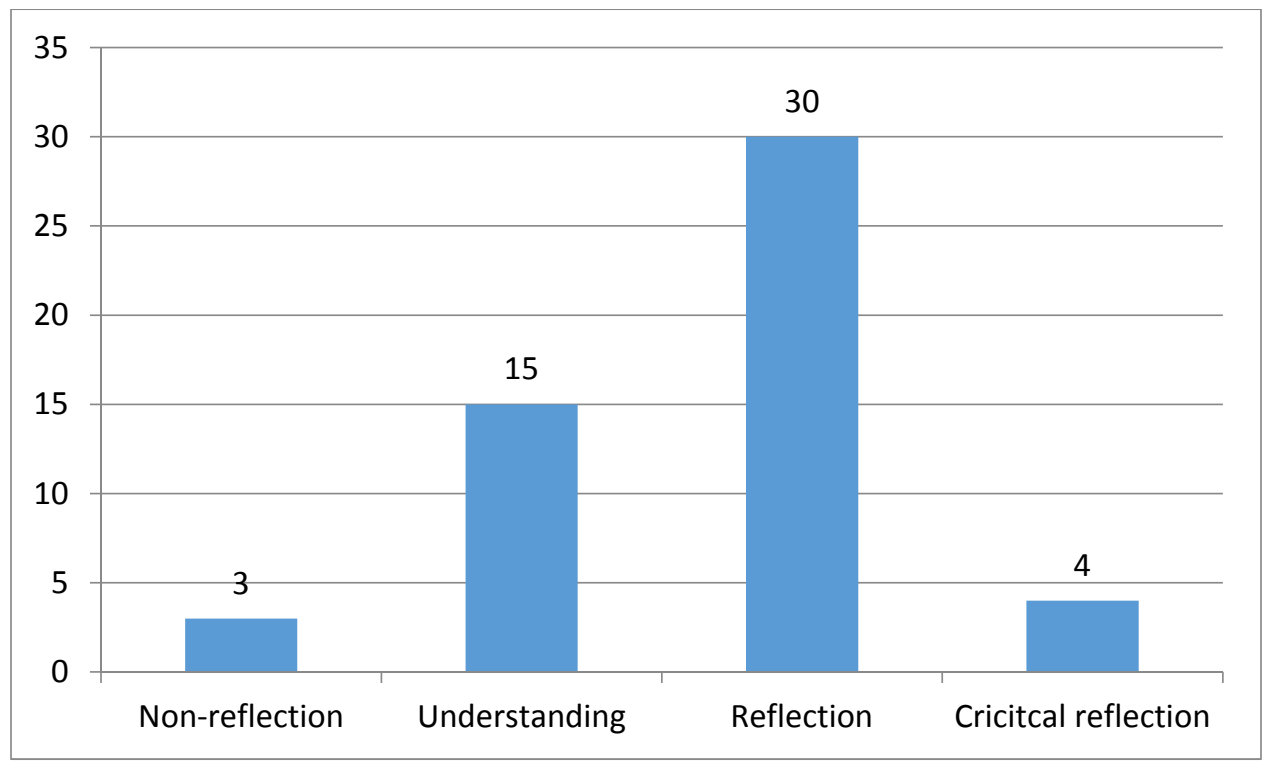

Figure 2: Overall levels of reflection

An analysis of the prompts (Figure 3) showed the decision making prompt yielded the highest single assessment count with reflection $(\mathrm{n}=10)$. The study of non-verbal cues yielded a high risk/high reward outcome with both the highest number of non-assessment and critical reflection classifications. The study of team roles, memory comparison, and quantitative analysis had zero non-reflection ratings.

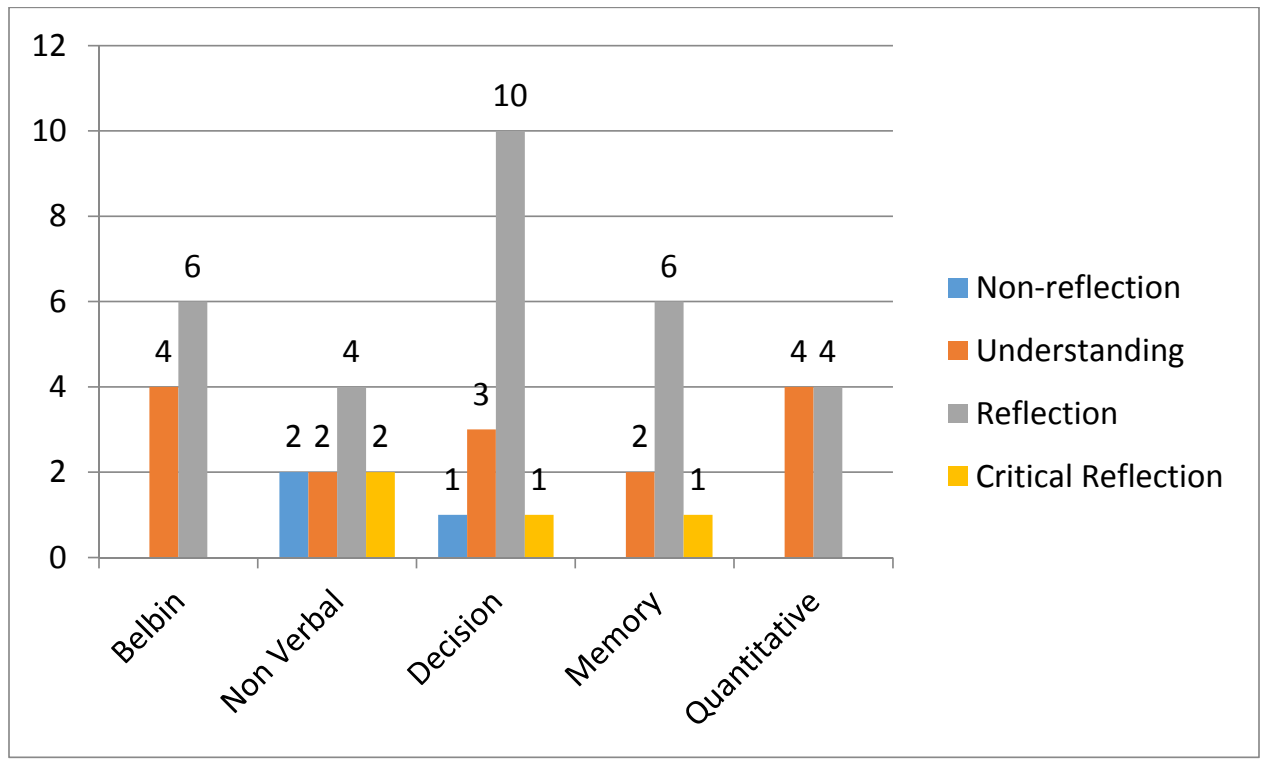

Figure 3: Levels of reflection by prompt

In terms of gender (Figure 4), women earned more reflection assessments $(n=19)$ then men $(\mathrm{n}=11)$ and men earned more non-reflection and understanding ratings $(\mathrm{n}=12)$ than women $(\mathrm{n}=5)$. Men and women earned the same number of critical reflection ratings $(\mathrm{n}=2)$. 


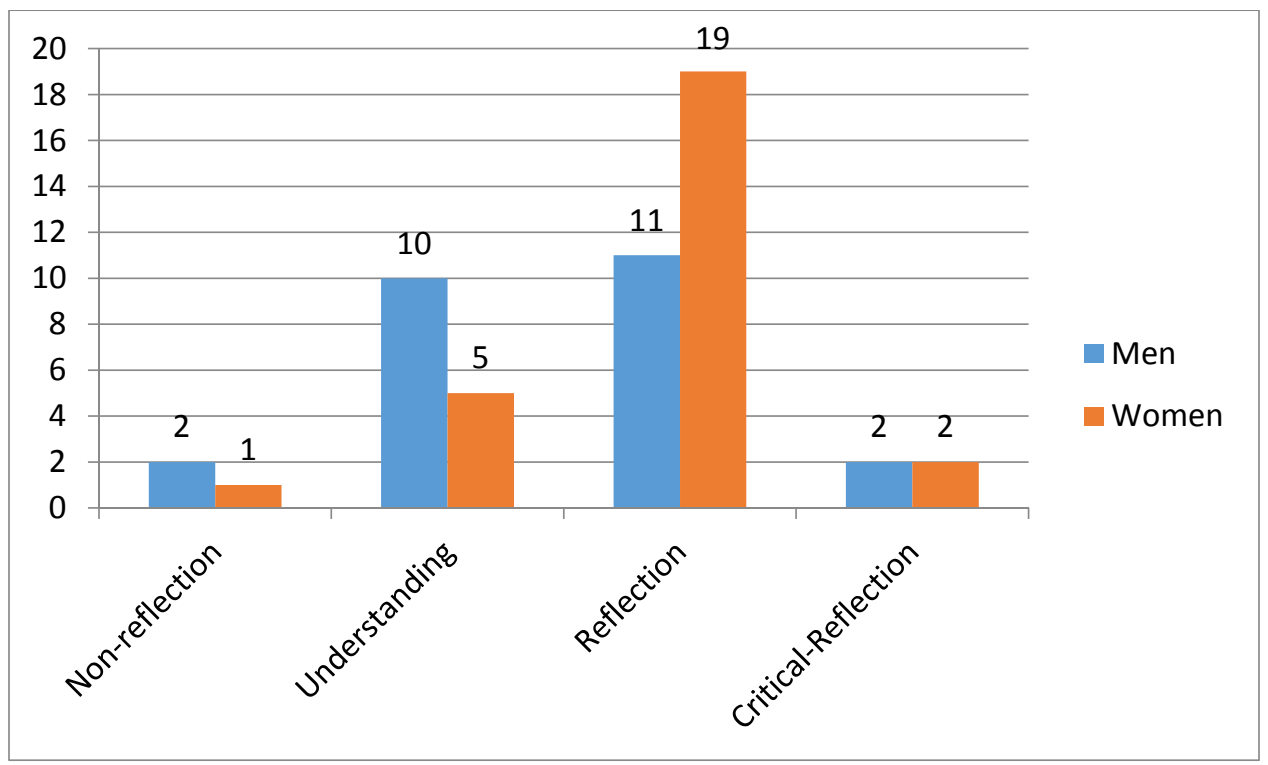

Figure 4: Levels of reflection by gender

For the purposes of statistical analysis of the levels of reflection, the ratings are treated as ordinal and non parametric. A Kruskall Wallis test for a statistically significant difference between each prompt and the levels of reflection gave the following values: chi-squared $=1.99$, $\mathrm{df}=4$, p-value $=0.74$. There was no statistically significant difference between prompts with the Kruskal Wallis test which may be a result of the small sample size.

Two sample Wilcoxon test for statistically significant differences between men and women in regards to their levels of reflection gave the following values: $\mathrm{W}=258.5$, $\mathrm{p}$-value $=0.10$. Testing for differences between gender for the corresponding level of reflection, there was no statistically significant difference.

When running the same test again but with non-reflection and understanding as one category, and reflection and critical-reflection levels together as another category, the following values were found: $\mathrm{W}=250.5$, $\mathrm{p}$-value $=0.055$. There is not enough evidence to support more than a trend between level of reflection and gender.

\section{Discussion}

\section{$\underline{\text { Initial Rubric }}$}

The initial rubric, which was derived from Kember ${ }^{7}$ and modified, was meant to be tailored for this specific reflection assignment. Unfortunately researchers found the inclusion of additional details, such as affect in the self-reflection, made assigning self-reflection levels more difficult, especially between understanding and reflection levels. 
The modified rubric was also interpreted to have each reflection level build on each other, in the sense that the previous levels of reflection were required to achieve a level higher than non-reflection. This slowed the research team down and made it more difficult to separate the four levels because papers could satisfy criteria on multiple levels.

Researchers also encountered problems assigning levels of reflection holistically, using either rubric, due to the format of the assignment. Students' essays were generally broken down into video analysis, suggestion for yourself, and suggestion for the team. Researchers could identify different levels of reflection occurring in the different sections, and this made it more difficult to assign a whole level of reflection to the entire paper. Researchers decided to round up to the highest level of reflection present between the self and team suggestions when coding independently, keeping in mind the information from the video analysis section. Typically, video analysis sections were highly descriptive in nature, but researchers often found that a more comprehensive video analysis led to more concrete suggestions and would often support a higher level of reflection.

\section{Levels of Reflection}

The percentage breakdown of the levels of reflection shows that over half of the student papers are a reflection or critical-reflection (Figure 2). Results show that the assignment, which is scaffolded with videos and prompts, works to provoke constructive levels of reflection in most of the students in the study. In this sense, students were able to return directly to the projectbased team experience by watching video of them, and from that experience the students were able to learn about how they interacted with the team, or how their team as a whole functioned.

Three papers (6\%) were assessed to be non-reflection. In these papers, there was either a lack of description of the events of the video, or the description in the paper was too vague. Invariably, these papers did not produce any discussion of the thoughts or actions that were present in the video of the design team meeting, though it was possible for the student to note that those thoughts or actions were present (Ex: "We get distracted, but Jade brings us back on task").

Fifteen papers (29\%) were assessed to be understanding. Students would describe the thoughts and actions present in the video, and would evaluate them based on an externalized quality (Ex: "If I ask for more group input about my suggestions, this will improve engagement and refine my own thoughts, as opposed to not involving myself in the discussion"). The student did connect the events of the video with a body of knowledge, but it was not apparent that the student has gained any knowledge from returning to the experience. For the above example, a reflection might entail that the student discusses why they weren't involved in the first place, and their suggestion for themselves would imply that the student has reevaluated their reason for non-participation. These students may experiment with new thoughts or actions after this 
assignment, based on their theoretical understanding. Ideally, understanding places the point at which the student performs reflection in the near future.

Thirty papers (58\%) were assessed to be reflection. As noted in the disagreements section, reflection papers had the three qualities; practicality, experience, and connection/personal insight; in common. All reflection papers satisfactorily demonstrated that the student learned something about themselves or their team after revisiting the events of the video. On the other hand, what was changed about the knowledge frameworks of these students was not so fundamental as to be labeled a critical-reflection.

\section{Critical-Reflection}

Kember describes critical-reflection in their rubric as "evidence of a change in perspective over a fundamental belief of the understanding of a key concept or phenomenon ${ }^{7}$." Using this criterion, the reader can attempt to identify whether each of these aspects are in a paper in order to determine if the paper demonstrates critical-reflection. Table 2 shows one example of what understanding, belief, and perspective can look like in a self-reflection essay.

With Student A, we hear about the state of the group. The student observes a natural tendency within the group to hesitate from participating in group discussions. After watching the video Student A sees herself putting ideas out to the group. She notices her teammates are acting on her ideas. She seems sincerely surprised by this and concludes this is happening because the group respects her ideas. She considers why she might be respected and what might undermine that respect in the future. In this sense, she takes a holistic approach to understanding the concept of respect and the different ways respect can be earned and lost in a team setting. She also thinks about the entire team and the benefits of mutual respect within the team. Evidence suggests an evolving framework that is shifting in real time.

Table 2: Examples of Critical Reflection

\begin{tabular}{|l|l|l|}
\hline \multicolumn{3}{|c|}{ Student A: Concept - Team Dynamics/Individual Contribution } \\
\hline $\begin{array}{l}\text { Aspect of } \\
\text { Critical } \\
\text { Reflection }\end{array}$ & Relation to student essay & Supporting Quote \\
\hline Understanding & $\begin{array}{l}\text { In order to direct the } \\
\text { team, ideas need to be } \\
\text { considered and } \\
\text { respected. }\end{array}$ & $\begin{array}{l}\text { "Everybody seems a bit hesitant to decide on it, it } \\
\text { seems as if I am the only one who [can] actually } \\
\text { put down my idea, but when I do, everybody seems } \\
\text { to agree." }\end{array}$ \\
\hline Belief & I am respected & "I hadn't noticed during the discussion how much \\
\hline
\end{tabular}




\begin{tabular}{|l|l|l|}
\hline & & respect everybody had for me and my ideas.” \\
\hline Perspective & $\begin{array}{l}\text { Respect does not just } \\
\text { happen }\end{array}$ & $\begin{array}{l}\text { "When you talk they will listen. They respect your } \\
\text { ideas, so be willing to admit your flaws because } \\
\text { other[s] might not." }\end{array}$ \\
\hline
\end{tabular}

\section{Conclusion}

\section{Engineering Student Reflection}

Based on our findings we believe engineering students learn a great deal about themselves and their teams when they have time to reflect on those experiences. A larger sample size may be required to satisfactorily tell whether or not there actually is a difference between prompts that are used to promote learning and the possible differences in gender ratings suggests the need for further research and confirmation in that area.

Though the assignment successfully produced desirable self-reflection outcomes, we feel the prompts can also be changed to have a general decrease in non-reflections and understandings and to have an increase in reflections and possibly critical-reflections. The prompt specifically asks for suggestions that would improve the meeting, and that may direct people towards non-reflection in more than one way. For one, they are only approaching the events of the meeting, and the conclusions drawn should extend beyond the scope of the meeting if meaning schemes and meaning perspectives are to be affected. Another way to enhance the prompts would be to focus on what's working within the group, shifting the focus from what's not working and needs fixing, to what's working and should be done again.

Borrowing from Hirsch and McKenna ${ }^{15}$, and from Greenwood ${ }^{25}$, we suggest that future prompts ask students to:

- Identify the behaviors in the video

- Identify the origins of their behaviors

- Identify the factors that contribute to an engineering team's success

- Provide suggestions only if they feel that they are needed

- Provide the reasons why they did or did not feel the need to provide suggestions, whether or not these reasons are rooted in the events of the video

The student should not be required to provide a suggestion in the case of a person who thought their team was very successful, as reflecting on success is also important ${ }^{1}$. Also, a valid assessment would not expect students to always have ineffective meaning schemes and perspectives ${ }^{29}$. The student should also not be limited to drawing on the events of the video, though they should be assisted by the video. Future prompts for reflection may also specifically 
ask for all three properties of reflection described in the original Kember rubric and detailed in the disagreements section.

\section{Critical Reflection}

Four critical-reflections were identified, with students testing the validity of their beliefs against their personal design team experience. This speaks to the potential value of self-reflection assignments and activities, as activities such as this can provide fertile ground for transformative experiences. Nussbaum and Novick suggest that meaning schemes and meaning perspectives may be a hindrance to learning if they are not identified and challenged ${ }^{25}$. Nussbaum and Novick write that this process of overcoming assumptions and allowing students to critically reflect, regardless of their "readiness" or in spite of their lack of awareness, is critical to developing their system of knowledge.

Implementing this process with current knowledge of how engineering students reflect will always be difficult because each student brings their own meaning schemes and perspectives. A personalized one-on-one interaction with a facilitator or peer may be one way of implementing the process. Another strategy is for researchers to continue gathering information about the concepts and assumption that students are most likely to need to reflect upon. An evidence-based intervention while somewhat limited in its content could be designed to address the more common assumptions that emerge on certain projects.

Additionally, we recommend instructors consider sharing the suggestions that the students generate with their teammates using an outside a facilitator. A facilitator could increase the potential for sharing insights that are team specific and the facilitator could help synthesize multiple observations into a single lesson. Sharing the reflections within the team could also lead to more buy-in by the students because the benefits of the self-reflection exercise move from the theoretical realm to the classroom floor. That said it is also possible that sharing insights could lead students to be more cautious in the reflections for fear of hurting a teammates feelings.

\section{Bibliography}

1. Sabag, N., Trotskovsky, E., \& Waks, S. (2013). Engineering design projects as a reflection promoter. European Journal of Engineering Education, 39(3), 309-324. doi: 10.1080/03043797.2013.867312

2. Kolb, D. A., Boyatzis, R. E., \& Mainemelis, C. (2001). Experiential learning theory: Previous research and new directions. Perspectives on Thinking, Learning, and Cognitive Styles, 227-247.

3. Tatar, N., Chachra, D., Zastavker, Y. V., \& Stolk, J. (2010, Oct 27-30). Work in Progress - Using Video and Self-Reflection to Enhance Undergraduate Teams. Paper presented at the 40th Annual Frontiers in Education Conference, Arlington, VA. 
4. Hulsman, R. L., Harmsen, A. B., \& Fabriek, M. (2009). Reflective teaching of medical communication skills with DiViDU: Assessing the level of student reflection on recorded consultations with simulated patients. Patient Education and Counseling, 74(2), 142-149. doi: http://dx.doi.org/10.1016/j.pec.2008.10.009

5. Marita, P., Leena, L., \& Tarja, K. (1999). Nurses' self-reflection via videotaping to improve communication skills in health counseling. Patient Education and Counseling, 36(1), 3-11. doi: 10.1016/s0738-3991(98)00069-x

6. Duke, S., \& Appleton, J. (2000). The use of reflection in a palliative care programme: a quantitative study of the development of reflective skills over an academic year. Journal of Advanced Nursing, 32(6), 1557-1568. doi: 10.1046/j.1365-2648.2000.01604.x

7. Kember, D., McKay, J., Sinclair, K., \& Wong, F. K. Y. (2008). A four-category scheme for coding and assessing the level of reflection in written work. Assessment \& Evaluation in Higher Education, 33(4), 369-379. doi: 10.1080/02602930701293355

8. Koole, S., Dornan, T., Aper, L., De Wever, B., Scherpbier, A., Valcke, M., . . Derese, A. (2012). Using video-cases to assess student reflection: Development and validation of an instrument. Bmc Medical Education, 12, 8. doi: 10.1186/1472-6920-12-22

9. Wong, F. K. Y., Kember, D., Chung, L. Y. F., \& Yan, L. (1995). ASSESSING THE LEVEL OF STUDENT REFLECTION FROM REFLECTIVE JOURNALS. Journal of Advanced Nursing, 22(1), 48-57. doi: 10.1046/j.1365-2648.1995.22010048.x

10. Kitchenham, A. (2008). The evolution of John Mezirow's transformative learning theory. Journal of transformative education, 6(2), 104-123.

11. Hirsch, P. L., \& McKenna, A. F. (2008). Using reflection to promote teamwork understanding in engineering design education. International Journal of Engineering Education, 24(2), 377-385.

12. Meyers, K. L., Silliman, S. E., Gedde, N. L., \& Ohland, M. W. (2010). A Comparison of Engineering Students' Reflections on Their First-Year Experiences. Journal Of Engineering Education, 99(2), 169-178.

13. Molee, L. M., Henry, M. E., Sessa, V. I., \& McKinney-Prupis, E. R. (2010). Assessing learning in servicelearning courses through critical reflection. Journal of Experiential Education, 33(3), 239-257.

14. Higgins, L., Flower, L., \& Petraglia, J. (1992). Planning Text Together The Role of Critical Reflection in Student Collaboration. Written communication, 9(1), 48-84.

15. Mezirow, J. (1990). How critical-reflection triggers transformative learning. Fostering critical-reflection in adulthood, 1-20.

16. Schön, D. A. (1983). The reflective practitioner: How professionals think in action (Vol. 5126): Basic books.

17. Blockley, D. (1992). Engineering from reflective practice. Research in Engineering Design, 4(1), 13-22.

18. Lawson, B. (2006). How designers think: the design process demystified: Routledge

19. Fischer, M. A., Haley, H. L., Saarinen, C. L., \& Chretien, K. C. (2011). Comparison of blogged and written reflections in two medicine clerkships. Medical Education, 45(2), 166-175. doi: 10.1111/j.1365-2923.2010.03814.x

20.Koole, S., Dornan, T., Aper, L., Scherpbier, A., Valcke, M., Cohen-Schotanus, J., \& Derese, A. (2012). Does reflection have an effect upon case-solving abilities of undergraduate medical students? Bmc Medical Education, 12, 5. doi: 10.1186/1472-6920-12-75

21. Kember, D. (1999). Determining the level of reflective thinking from students' written journals using a coding scheme based on the work of Mezirow. International Journal of Lifelong Education, 18(1), 18-30.

22. Plack, M. M., Driscoll, M., Blissett, S., McKenna, R., \& Plack, T. P. (2005). A method for assessing reflective journal writing. Journal of allied health, 34(4), 199-208.

23. Chan, C. K. Y. (2012). Exploring an experiential learning project through Kolb's Learning Theory using a qualitative research method. European Journal of Engineering Education, 37(4), 405-415.

24. Walther, J., Radcliffe, D., \& Mann, L. (2007, Oct 10-13). Analysis of the use of an accidental competency discourse as a reflective tool for professional placement students. Paper presented at the 37th Annual Frontiers in Education Conference, Milwaukee, WI. 
25. Nussbaum, J., \& Novick, S. (1982). ALTERNATIVE FRAMEWORKS, CONCEPTUAL CONFLICT AND ACCOMMODATION - TOWARD A PRINCIPLED TEACHING STRATEGY. Instructional Science, 11(3), 183-200. doi: 10.1007/bf00414279

26. Viera, A. J., \& Garrett, J. M. (2005). Understanding interobserver agreement: the kappa statistic. Family Medicine, 37(5), 360-363.

27. Bell, A. E., Spencer, S. J., Iserman, E., \& Logel, C. E. R. (2003). Stereotype Threat and Women's Performance in Engineering. Journal of Engineering Education, 92(4), 307-312.

28. Greenwood, J. (1998). The role of reflection in single and double loop learning. Journal of Advanced Nursing, 27(5), 1048-1053. doi: 10.1046/j.1365-2648.1998.t01-1-00579.x

29. Bell, A., Kelton, J., McDonagh, N., Mladenovic, R., \& Morrison, K. (2011). A critical evaluation of the usefulness of a coding scheme to categorise levels of reflective thinking. Assessment \& Evaluation in Higher Education, 36(7), 797-815. doi: 10.1080/02602938.2010.488795

30. Ixer, G. (1999). There's no such thing as reflection. British Journal of Social Work, 29(4), 513-527.

31. Heath, C., \& Hindmarsh, J. (2002). Analysing Interaction. Video Ethnography.

32. Stokoe, E. H., \& Smithson, J. (2001). Making gender relevant: conversation analysis and gender categories in interaction. Discourse \& Society, 12(2), 217-244. doi: 10.1177/0957926501012002005

33. Crismond, D. P., \& Adams, R. S. (2012). The Informed Design Teaching and Learning Matrix. Journal of Engineering Education, 101(4), 738-797.

34. Jordan, B., \& Henderson, A. (1995). Interaction analysis: Foundations and practice. Journal of the Learning Sciences, 4(1), 39-103. doi: 10.1207/s15327809jls0401_2 